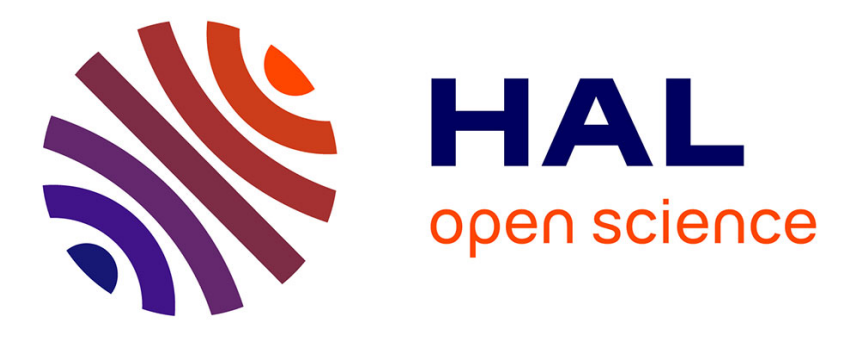

\title{
Effect of alkalis on the Fe oxidation state and local environment in peralkaline rhyolitic glasses
}

Gabriele Giuli, Roberto Alonso-Mori, Maria Rita Cicconi, Eleonora Paris, Pieter Glatzel, Sigrid-Griet Eeckhout, Bruno Scaillet

\section{To cite this version:}

Gabriele Giuli, Roberto Alonso-Mori, Maria Rita Cicconi, Eleonora Paris, Pieter Glatzel, et al.. Effect of alkalis on the Fe oxidation state and local environment in peralkaline rhyolitic glasses. American Mineralogist, 2012, 97 (2-3), pp.468-475. 10.2138/am.2012.3888 . insu-00681280

\section{HAL Id: insu-00681280 \\ https://hal-insu.archives-ouvertes.fr/insu-00681280}

Submitted on 21 May 2012

HAL is a multi-disciplinary open access archive for the deposit and dissemination of scientific research documents, whether they are published or not. The documents may come from teaching and research institutions in France or abroad, or from public or private research centers.
L'archive ouverte pluridisciplinaire HAL, est destinée au dépôt et à la diffusion de documents scientifiques de niveau recherche, publiés ou non, émanant des établissements d'enseignement et de recherche français ou étrangers, des laboratoires publics ou privés. 
Effect of alkalis on the Fe oxidation state and local environment in peralkaline rhyolitic obsidians.

Gabriele Giuli ${ }^{1}$, Roberto Alonso Mori ${ }^{1,2 \ddagger}$, Maria Rita Cicconi ${ }^{1}$, Eleonora Paris ${ }^{1}$, Pieter Glatzel $^{2}$, Sigrid Griet Eeckhout ${ }^{2, \S}$, and Bruno Scaillet ${ }^{3}$.

${ }^{1}$ School of Science and Technology, Geology Division, University of Camerino, Italy

${ }^{2}$ European Synchrotron Radiation Facility, Grenoble, France.

${ }^{3}$ Inst. Sciences de la Terre d' Orleans, UMR6113 CNRS-UO, Orleans, France

Running title: Fe oxidation state in peralkaline rhyolitic glasses

Corresponding author: Gabriele Giuli

$$
\begin{aligned}
& \text { Tel. +39-0737-402606 FAX +39-0737-402644 } \\
& \text { e-mail: gabriele.giuli@ unicam.it }
\end{aligned}
$$

${ }^{\star}$ Current address: SLAC, Stanford University, USA.

$\S$ Current address: ONDRAF/NIRAS, Avenue des Arts 14, 1210 Brussels, Belgium. 


\begin{abstract}
Fe oxidation state and coordination geometry have been determined by Fe K-edge XANES (X-ray Absorption Near edge Spectroscopy) for three sets of silicate glasses of peralkaline rhyolitic composition with different peralkalinity values. These compositions have been chosen to investigate the effect of alkali content (and oxygen fugacity) on the $\mathrm{Fe}$ oxidation state. The samples have been produced by means of hydrothermal vessels at $800^{\circ} \mathrm{C}$ with oxygen fugacity conditions ranging from NNO-1.61 to NNO+2.96 log units.

Comparison of the pre-edge peak data with those of Fe model compounds with known oxidation state and coordination number allowed to determine the Fe oxidation state and coordination number in all the glasses analysed. Within each group of samples, Fe tends to oxidise with increasing oxygen fugacity as expected. However, alkali content is shown to have a strong effect on the $\mathrm{Fe}^{3+} /\left(\mathrm{Fe}^{3+}+\mathrm{Fe}^{2+}\right)$ ratio at constant oxygen fugacity: this ratio varies from 0.25 to $0.55( \pm 0.05)$ for the least peralkaline series, and from 0.45 to $0.80( \pm 0.05)$ for the most peralkaline series. Moreover, pre-edge peak data clearly indicate that $\mathrm{Fe}^{3+}$ is in [4] coordination in the most peralkaline glasses. Extrapolation of pre-edge peak data suggests the presence of both [4] and [5] coordination for trivalent Fe in the other two series. Divalent Fe is suggested to be mainly in [5] coordination in all the three glass series. The presence of minor amounts of [6] and [4] coordinated Fe cannot be ruled out by XANES data alone. XANES data suggest that the amount of alkalis also affects $\mathrm{Fe}^{3+}$ coordination environment decreasing the average coordination numbers.
\end{abstract}

EXAFS (Extended X-ray Absorption Fine Structure) data of the most oxidised and peralkaline sample indicate that $\mathrm{Fe}^{3+}$ is in tetrahedral coordination with $\langle\mathrm{Fe}-\mathrm{O}\rangle=1.85 \AA$ $( \pm 0.02)$. This value compares well with literature data for ${ }^{[4]} \mathrm{Fe}^{3+}$ in crystalline phases (e.g. in 
tetra-ferriphlogopite or rodolicoite) or in silicate glasses (e.g. phonolite glasses) supporting the XANES-determined coordination number obtained for the most peralkaline glasses.

Calculated NBO/T ratios decrease slightly with $\mathrm{Fe}$ oxidation because of the higher fraction of network forming Fe, thus increasing the polymerisation of the tetrahedral network.

Keywords: Iron local environment, rhyolitic glasses, EXAFS, XANES, alkalis

\section{INTRODUCTION}

Transition elements can affect glass/melts properties such as density, viscosity, and refraction index (see Mysen and Richet 2005). Moreover, their structural role in the melt affects their partition coefficients between melt and crystals in natural systems and is therefore important to understand the behaviour of minor to trace elements during crystallization. The knowledge of the control exerted by melt composition, $\mathrm{P}, \mathrm{T}$, and $\mathrm{fo}_{2}$ conditions on the local structure of the transition elements is therefore of fundamental importance in relating the atomistic structure of silicate melts to their macroscopic properties. Despite the importance of these data, this is a topic where ample debate still exhists and many studies and spectroscopic techniques have been employed in the aim of clarifying the structural role of transition elements.

Iron, the most common transition element in natural magmas, can exist in silicate melts in a variety of oxidation states and coordination numbers. Common Fe species in silicate melts and glasses include ${ }^{[4]} \mathrm{Fe}^{2+},{ }^{[5]} \mathrm{Fe}^{2+},{ }^{[4]} \mathrm{Fe}^{3+}$, and ${ }^{[5]} \mathrm{Fe}^{3+}$ (see Wilke et al. 2001, 2006; Rossano et al. 2000, 2008; Jackson et al. 1993, 2005; Giuli et al. 2002, 2005, 2008; Magnien et al., 2004); in few cases, also a minor presence of ${ }^{[6]} \mathrm{Fe}^{3+}$ (Wilke et al. 2004) and ${ }^{[6]} \mathrm{Fe}^{2+}$ (Calas and Petiau, 1983; Virgo and Mysen, 1985;) has been reported. Variation of the relative proportions of 
these species implies variations in $\langle\mathrm{Fe}-\mathrm{O}\rangle$ distances and bond strenghts, thus affecting glass/melt polymerisation, partial molar volumes of Fe species, melt density and viscosity. As varying oxygen fugacity affects the Fe oxidation state of a melt, oxygen fugacity can be expected to trigger considerable variations also in the viscosity of melts where Fe is a major element (Cukierman and Uhlman, 1974; Dingwell, 1991; Giuli et al. 2011; Dingwell et al. 2008).

More generally, Fe can affect considerably the melt structure and all related properties in silicate melts/magmas, when present in major amounts, in relation to a number of variables like P, T, oxygen fugacity, bulk melt composition. Alkali content is also known to affect Fe oxidation state in silicate melts (see Duffy 1992, 1996; Moretti and Ottonello, 2003 and references therein), but no measurements are available up to now to quantitatively assess to which extent alkalis can modify Fe structural role in glasses/melts. For this reason in this work we investigated the Fe structural role and oxidation state in three series of synthetic Sbearing rhyolite glasses characterised by different peralkalinity and produced in a range of different oxygen fugacity conditions to study the effect of the alkali content on the Fe oxidation state.

\section{MATERIALS AND METHODS}

The glasses were produced in the frame of a sulphur solubility study by Scaillet and Mc Donald (2006). Three compositions were chosen using well characterised peralkaline rhyolitic obsidians from the Naivasha area and the Kenya Rift Valley: two mildly peralkaline comendites (ND and SMN) and a pantalleritic obsidian (EBU). These compositions display a range of $\left(\mathrm{Na}_{2} \mathrm{O}+\mathrm{K}_{2} \mathrm{O}\right) / \mathrm{Al}_{2} \mathrm{O}_{3}$ ratios (from $1.05,1.31$ to 1.88 for the $\mathrm{ND}$, SMN and $\mathrm{EBU}$ respectively) and $\mathrm{Fe}$ contents $(0.63,2.11$ and 4.96 total $\mathrm{FeO}$ for ND, SMN and EBU 
respectively). Powdered glasses, mixed with 1 wt $\% \mathrm{~S}$, were sealed in Au capsules and held at $800{ }^{\circ} \mathrm{C} 1.2 \mathrm{kbar}$ in cold seal pressure vessels fitted with $\mathrm{H}_{2}$ membrane. The $\mathrm{fo}_{2}$ was varied with $\mathrm{Ar}-\mathrm{H}_{2}$ mixtures. More experimental details on the synthesis can be found in Scaillet and Mc Donald (2006). The compositions of the resulting glasses are reported in Table 1 in the form of weight percent oxide content. The $\mathrm{Fe}$ content (originally as total $\mathrm{FeO}$ ) has been partitioned between $\mathrm{FeO}$ and $\mathrm{Fe}_{2} \mathrm{O}_{3}$ according to the XANES determined $\mathrm{Fe}^{3+} /\left(\mathrm{Fe}^{3+}+\mathrm{Fe}^{2+}\right)$ ratio. The polymerisation of the tetrahedral network has been expressed as NBO/T ratio according to the procedure by Mysen and Richet (2005). In order to calculate the amount of tetrahedrally coordinated cations, $\mathrm{Al}$ and $\mathrm{Si}$ have been considered to be present as [4]coordinated whereas $\mathrm{Fe}^{2+}$ as [5]-coordinated and $\mathrm{Fe}^{3+}$ as [4] and/or [5]-coordinated according to the XANES data of the samples.

Samples for absorption measurements were prepared as glass fragments embedded in resin with a finely polished surface. The standards used for XANES measurements are: a staurolite from Canton Ticino (Switzerland) and a synthetic $\mathrm{Fe}$-akermanite for $\mathrm{Fe}^{2+}$ in tetrahedral coordination; a grandidierite from Madagascar for $\mathrm{Fe}^{2+}$ in trigonal dipyramidal coordination; a synthetic kirschsteinite, and a siderite from Erzberg (Austria) for $\mathrm{Fe}^{2+}$ in octahedral coordination; a natural andradite from Italy, and a natural aegirine from Malawi for $\mathrm{Fe}^{3+}$ in octahedral coordination; a natural yoderite from Mautia Hills (Tanzania) for $\mathrm{Fe}^{3+}$ in 5fold coordination; a tetra-ferriphlogopite from Tapira (Brasil) for $\mathrm{Fe}^{3+}$ in 4-fold coordination (Giuli et al. 2001). The natural standards were separated by hand picking from thumb-sized crystals choosing the clearest portions to avoid impurities. All the standards were checked for purity by both optical microscopy and X-ray diffraction.

Model compounds for XAS measurement were prepared by smearing finely ground powder on a kapton tape, whereas the glass samples were prepared as slides with polished surfaces. The flat sample surface was placed at $45^{\circ}$ from the X-ray beam directed towards the 
fluorescence detector. Fe K-edge XANES spectra were recorded at room temperature at the ESRF on the undulator beamline ID26 (Gauthier et al. 1999, Solé et al. 1999) operating at 6 $\mathrm{GeV}$ in 16 bunch filling mode. A fixed-exit $\mathrm{Si}(311)$ double-crystal monochromator was used, providing an energy resolution of $\sim 0.2 \mathrm{eV}$ at the Fe K-edge. However, the main limitation for energy resolution is the finite core-hole width of the absorbing element $(\sim 1.15 \mathrm{eV}$ at the $\mathrm{Fe}$ K-edge; Krause and Oliver 1979), resulting in a convoluted energy resolution (FWHM) of $1.4 \mathrm{eV}$. The energy was calibrated by defining the first derivative peak of a metallic $\mathrm{Fe}$ reference foil to be at $7112.0 \mathrm{eV}$. Energy reproducibility has been tested by multiple collection some Fe model compound; the precision has been found to be within $\pm 0.05 \mathrm{eV}$ or better. Two Si mirrors were used for the harmonics rejection of the incident X-ray beam. Beam dimension at the sample was 150x300 micrometers. XANES data were recorded in quick-scan mode by simultaneously scanning the monochromator angle and the undulator gap with a typical energy step of $0.1 \mathrm{eV}$ and counting $44 \mathrm{~ms}$ per point. Each scan took 120 seconds and an average of 12 spectra was taken per sample. The spectra were acquired in fluorescence mode, using a $\mathrm{Si}$ photo-diode, and $\mathrm{I}_{0}$ was monitored by measuring the fluorescence signal of a titanium foil using a Si photo-diode. The sample was positioned at $45^{\circ}$ with respect to the beam and the detector.

\section{DATA REDUCTION}

Experimental XANES spectra were reduced by background subtraction with a linear function and then normalised for atomic absorption on the average absorption coefficient of the spectral region from 7170 to $7350 \mathrm{eV}$. The threshold energy was taken as the first maximum of the first derivative of the spectra, whereas peak positions were obtained by calculating the second derivative of the spectra. Pre-edge peak analysis was carried out 
following the same procedure reported in Wilke et al. (2001), Farges (2001), and Giuli et al. (2002). The pre-edge peak region was analyzed by first subtracting an arctangent background from the normalised spectra and then by fitting the pre-edge peak by a sum of pseudo-Voigt functions. Pre-edge peak intensities along with energy positions were compared with those of the standards analysed here and others from the literature (e.g., Wilke et al. 2001; Farges 2001) in order to extract information on Fe oxidation state and coordination number in the glasses studied. Particular care was taken in using the smallest possible number of components in the pre-edge peak fitting procedure. In particular, the number (and, in some cases, the approximate energy) of the components was constrained to equal the number (and approximate energy) of the minima in the second derivative spectrum of the pre-edge peak. Several procedures have been tried for the pre-edge peak fitting: (1) simultaneous fitting of the background and the pseudo-Voigt component; (2) preliminary background subtraction followed by fitting with pseudo-Voigt component allowing the components to have different FWHM or Lorentian character; (3) preliminary background subtraction followed by fitting with pseudo-Voigt component constrained to have the same FWHM and Lorentian character. The third procedure produced the best results in terms of scatter of pre-edge peak integrated intensity and centroid energy (Giuli et al. 2011). In particular, reproducibility of the integrated intensity has been estimated to be within \pm 0.002 by performing several fits to the background subtracted pre-edge peaks. Use of different procedures for arctangent background subtraction, however, can lead to higher errors in the integrated intensity, up to \pm 0.035 .

The energy-intensity data of the fitted pre-edge peaks were compared with mixing lines calculated as intensity-weighted averages of 2 end-members: for divalent iron an ideal preedge peak has been chosen with integrated intensity equal to 0.11 and an energy $0.9 \mathrm{eV}$ above the edge energy of metallic iron; for trivalent iron several possible pre-edge peak data have 
been used in the calculation of mixing lines with integrated intensity ranging from 0.2 to 0.35 and with an energy $2.4 \mathrm{eV}$ above the edge energy of metallic iron.

EXAFS data reduction and analysis was done by means of the GNXAS package (Filipponi and Di Cicco 2000). This program extracts the EXAFS signal $(\chi(\mathrm{k}))$ from the raw spectrum without performing Fourier filtering and thus avoids possible bias derived from incorrect background subtraction. The theoretical amplitudes and phase shifts are calculated $\mathrm{ab}$ initio according to the muffin-tin approximation. The Hedin-Lundquist complex potential (Hedin and Lundquist 1971) was used for the exchange-correlation potential of the excited state. The amplitude reduction factor $\left(\mathrm{S}_{0}{ }^{2}\right)$ has been fixed to 0.83 , in agreement with the values observed for several crystalline standard and natural glasses (Giuli et al. 2002). This value is close to that used by Farges et al. (1994) of 0.82, and that used by Di Cicco et al. (1994) of 0.85.

\section{RESULTS}

\subsection{XANES}

Fe K-edge XANES spectra of the silicate glasses are shown in Figure 1a, 1b, and 1c arranged in order of increasing oxygen fugacity (ranging from NNO-1.61 to NNO+ $2.96 \mathrm{log}$ units) from bottom to top. An evident increase of the edge energy is visible with increasing oxygen fugacity. Moreover, clear variations are visible in the edge region in the shape of the absorption maximum and in the intensity and energy position of the pre-edge peak $\mathrm{P}$. These changes can be related to a variation in the Fe oxidation state and local structure.

This peak (P) is due to a $s$ - $d$ like electronic transition. Despite it is dipole-forbidden, it becomes partially allowed by mixing of the $d$-states of the transition metal with the $p$-states of 
the surrounding oxygen atoms. This implies that the pre-edge peak energy position and intensity are greatly affected by the average Fe oxidation state and coordination geometry (Calas and Petiau 1983a, 1983b; Brown et al. 1995; Wilke et al. 2001). In particular, accurate evaluation of the pre-edge peak centroid energy and integrated intensity and comparison with those of Fe model compounds can provide quantitative information on both Fe oxidation state and coordination environment (see Wilke et al. 2001; Farges 2001; Giuli et al. 2002): its intensity will be minimal in case of regular octahedral symmetry $\left(\mathrm{O}_{\mathrm{h}}\right)$ around the absorber, whereas it will reach its maximum in the case of tetrahedral coordination $\left(\mathrm{T}_{\mathrm{d}}\right)$.

The background subtracted pre-edge peaks are shown in Figure 2a,b,c along with the pseudo-Voigt components and their sums, whereas their centroid energies and integrated intensity are reported in Table 2. Each pre-edge peak has been fitted with three components whose energies (ca. 7112.6, 7113.9, and 7114.5 eV) are fairly consistent with those of $\mathrm{Fe}$ model compounds. In particular, while the first and last components can be ascribed to contributions from $\mathrm{Fe}^{2+}$ and $\mathrm{Fe}^{3+}$ respectively, the component at intermediate energy results from contributions by both divalent and trivalent Fe. The relative importance of divalent or trivalent Fe causes an increase of the respective components resulting in an energy shift of the pre-edge peak centroid. The integrated intensity of the pre-edge peaks vs. their centroid energies are plotted in Figure 3 along with the data of Fe model compounds analysed here and elsewhere (Wilke et al. 2001; Farges 2001; Giuli et al. 2002). For the sake of simplicity, the relative energy is plotted ( 0 refers to the first maximum of the first derivative of metallic $\mathrm{Fe}$ spectrum) in order to avoid confusions when comparing data with literature data where a different edge energy value for metallic Fe has been chosen.

All divalent $\mathrm{Fe}$ model compounds plot at energies close to $0.9 \mathrm{eV}$ above the metallic $\mathrm{Fe}$ edge, whereas trivalent $\mathrm{Fe}$ model compounds plot at energies close to $2.5 \mathrm{eV}$. At constant energy, the intensity of the model compounds pre-edge peaks varies according to the Fe 
coordination geometry (the shaded ellipses refer to the range of coordination numbers in $\mathrm{Fe}$ model compounds).

In order to obtain quantitative data on Fe oxidation state and coordination number, mixing lines have been calculated between pre-edge peak intensity and energy values representative of possible $\mathrm{Fe}$ structural roles in silicate glasses (e.g. ${ }^{[4]} \mathrm{Fe}^{2+},{ }^{[5]} \mathrm{Fe}^{2+},{ }^{[4]} \mathrm{Fe}^{3+}$, $\left.{ }^{[5]} \mathrm{Fe}^{3+},{ }^{[6]} \mathrm{Fe}^{3+}\right)$. All the pre-edge peak data are compatible with the presence of ${ }^{[5]} \mathrm{Fe}^{2+},{ }^{[4]} \mathrm{Fe}^{3+}$ and ${ }^{[5]} \mathrm{Fe}^{3+}$; thus, in Figure 3 we show several mixing lines (dotted) between pre-edge peak values appropriate to these $\mathrm{Fe}$ species. The determined $\mathrm{Fe}^{3+} /\left(\mathrm{Fe}^{3+}+\mathrm{Fe}^{2+}\right)$ are then plotted in Fig. 4 as a function of experimental redox conditions.

$\mathrm{The}^{3+} /\left(\mathrm{Fe}^{3+}+\mathrm{Fe}^{2+}\right)$ ratio varies systematically with oxygen fugacity within each series. For the ND series the $\mathrm{Fe}^{3+} /\left(\mathrm{Fe}^{3+}+\mathrm{Fe}^{2+}\right)$ ratio varies from 0.25 to $0.55( \pm 0.05)$. However, increasing the alkali content strongly affects the Fe oxidation state: in fact, the $\mathrm{Fe}^{3+} /\left(\mathrm{Fe}^{3+}+\right.$ $\mathrm{Fe}^{2+}$ ) ratio varies from 0.50 to 0.75 for the SMN series and from 0.45 to 0.80 for the EBU series.

In the same figure (Figure 3) it is shown that the silicate glasses data plot within three different region which form a trend of progressive oxidation. Despite every series has been synthesised in the same oxygen fugacity range, there is a clear shift to higher energy (i.e. to higher $\mathrm{Fe}$ oxidation states) with increasing $(\mathrm{Na}+\mathrm{K}) / \mathrm{Al}$ ratio (from 1.04 for ND to 1.31 for SMN and 1.81 for EBU). The trend observed in Figure 3 shows that, the higher is the alkali content, the higher the energy and intensity of the pre-edge peak. Despite the composition of the glasses is complex and involves changes also in the Fe content, this supports the idea that alkalis content strongly affects Fe oxidation state as well as Fe coordination number, producing more tetrahedral $\mathrm{Fe}^{3+}$ in the glass.

\subsection{Fe coordination environment}


The integrated intensities of the glasses pre-edge peaks can provide information on the average Fe coordination number and thus on the Fe coordination environment. The intensity chosen for divalent $\mathrm{Fe}$ to calculate the mixing lines is close to that of grandidierite, thus suggesting that divalent $\mathrm{Fe}$ is mostrly five-fold coordinated in all these glasses. However, we must keep in mind that this result comes from extrapolating the pre-edge intensities of all glasses to lower energy and still represents a guess. Furthermore, it represents an average coordination number and, in principle, can be explained also by the presence of both ${ }^{[4]} \mathrm{Fe}^{2+}$, ${ }^{[6]} \mathrm{Fe}^{2+}$ or, alternatively, of ${ }^{[4]} \mathrm{Fe}^{2+},{ }^{[5]} \mathrm{Fe}^{2+}$, and ${ }^{[6]} \mathrm{Fe}^{2+}$. However, experience on many natural and synthetic glasses (e.g. Giuli et al. 2002, 2003, 2005, 2008, 2011) for which both XANES and EXAFS data are available, suggests the presence of predominant ${ }^{[4]} \mathrm{Fe}^{2+}$ and ${ }^{[5]} \mathrm{Fe}^{2+}$, whereas only rarely is ${ }^{[6]} \mathrm{Fe}^{2+}$ found to be important; thus we propose that in the glasses studied here divalent Fe is present mainly in [5] (five-fold) coordination. On the other hand, trivalent $\mathrm{Fe}$ is clearly present in a different coordination environment. Comparison with mixing lines is consistent with higher pre-edge peak intensity of the trivalent Fe end-members when going from the ND to EBU series, thus suggesting a lower $\mathrm{Fe}^{3+}$ coordination number with increasing $\left(\mathrm{Na}_{2} \mathrm{O}+\mathrm{K}_{2} \mathrm{O}\right) / \mathrm{Al}_{2} \mathrm{O}_{3}$ ratio. It must be noted that, despite the paucity of standards with four-fold and five-fold coordinated iron, there is sometimes a considerable scatter in the pre-edge peak integrated intensity of standards with the same coordination number and oxidation state, especially for tetracoordinated $\mathrm{Fe}^{2+}$ and $\mathrm{Fe}^{3+}$. This scatter introduces a large error in the quantitative determination of the coordination number of our samples: while the pre-edge peaks of standards with ${ }^{[5]} \mathrm{Fe}^{2+}$ have integrated intensity at or very close to 0.1 , the integrated intensity of the pre-edge peaks of standards with ${ }^{[4]} \mathrm{Fe}^{3+}$ range from 0.24 to 0.40 (see Table 2). Thus, depending on which standards are taken into consideration, the resulting average coordination number of the glasses examined can vary considerably. We tentatively suggest that trivalent Fe is found mainly in [4] coordination in the EBU series and 
in a mixture of [4] and [5] coordination for the SMN and ND series. Should ${ }^{[6]} \mathrm{Fe}^{2+}$ or ${ }^{[6]} \mathrm{Fe}^{3+}$ be present in consistent amounts, the pre-edge peak intensity would be sensibly lower. However, their presence in minor amounts cannot be ruled out by XANES data alone. It is worth remarking that The fraction of tetrahedral Fe3 + increases at increasing alkali content

\subsection{EXAFS}

The experimental, theoretical and residual EXAFS signals of the EBU3 glass are shown in Figure 5a, whereas their Fourier transforms are shown in Figure 5b (see Table 3 with the essential parameters of the EXAFS fit). The EBU3 has been chosen for EXAFS analysis because it displays the highest $\mathrm{Fe}^{3+} /\left(\mathrm{Fe}^{3+}+\mathrm{Fe}^{2+}\right)$ ratio well in the field of ${ }^{[4]} \mathrm{Fe}^{3+}$, and it is therefore suitable to quantitatively determine the coordination environment of trivalent iron in these series.

Figure 5 shows that the fit is fairly satisfactory. Attempts to refine a distribution of different Fe-O distances did not improve the quality of the fit and resulted in convergence of the 2 or more theoretical signals to the same distance value. In the best fit of the EBU3 EXAFS spectrum, Fe was found to be tetrahedrally-coordinated $(\mathrm{N}=4 \pm 0.5)$ with a $\langle\mathrm{Fe}-\mathrm{O}\rangle$ distance equal to $1.84 \AA( \pm 0.02)$. This distance is close to that found in a ${ }^{[4]} \mathrm{Fe}^{3+}$ crystalline standard (1.86 $₫ 0.02$ for tetrahedrally coordinated Fe in tetra-ferriphlogopite; Giuli et al. 2001), and in other synthetic silicate glasses already characterised by XAS (Giuli et al. 2011) where trivalent $\mathrm{Fe}$ has been found to be in tetrahedral coordination and with similar bond distances $(1.85 \pm 0.01 \AA$ ). Thus the data obtained by EXAFS analysis confirms the indications on the Fe coordination number derived from the XANES spectra of this sample.

\section{DISCUSSION AND CONCLUSIONS}


XANES spectra of three series of glasses produced in a range of oxygen fugacity display clear changes in the shape, edge energy position, pre-edge peak position and intensity which point out to major changes in the Fe oxidation state and coordination number as a function of both bulk melt composition and oxygen fugacity. The experimental pre-edge peak data form a gross trend going from values compatible with the presence of ${ }^{[5]} \mathrm{Fe}^{2+}$ species only to a region compatible with a mixture of ${ }^{[4]} \mathrm{Fe}^{3+}$, and ${ }^{[5]} \mathrm{Fe}^{3+}$ (see Figure 3), although the presence of minor ${ }^{[6]} \mathrm{Fe}^{2+}$ or ${ }^{[6]} \mathrm{Fe}^{3+}$ cannot be excluded from XAS data alone. The scatter of all the data points within the calculated mixing line indicates that the ratio between ${ }^{[4]} \mathrm{Fe}^{3+}$ and ${ }^{[5]} \mathrm{Fe}^{3+}$ species is not constant through all the oxygen fugacity conditions studied. Exact estimation of the ratio between ${ }^{[4]} \mathrm{Fe}^{3+}$ and ${ }^{[5]} \mathrm{Fe}^{3+}$ species is hindered by the wide range of pre-edge peak integrated intensities of $\mathrm{Fe}$ model compounds. However, it is reasonable to assume that the average coordination number of divalent Fe is [5] in all the samples, whereas trivalent Fe can be in [4] coordination in the EBU series and in a mixture of [4] and [5] coordination in the SMN and ND series. The observed decrease of the average Fe coordination number at increasing alkali content is in agreement with data from Spiering and Seifert (1985) and Iwamoto et al. (1978). However it should be noticed that, assuming that all the trivalent iron is tetrahedrally coordinated in the EBU series, whereas about half of the trivalent iron is tetrahedrally coordinated in the ND and SMN series, the ratio between the sum of alkalis and tetrahedral Al and $\mathrm{Fe}^{3+}$ is always greater than one $\left[\left\langle(\mathrm{Na}+\mathrm{K}) /\left({ }^{[4]} \mathrm{Al}+{ }^{[4]} \mathrm{Fe}^{3+}\right)\right\rangle \sim 1.01,1.26\right.$ and 1.45 for the ND, SMN and EBU series respectively].

XANES determined $\mathrm{Fe}^{3+} /\left(\mathrm{Fe}^{2+}+\mathrm{Fe}^{3+}\right)$ ratio range from 0.25 to $0.55( \pm 0.05)$ for the least peralkaline series (ND), from 0.51 to $0.75( \pm 0.05)$ for the mildly peralkaline series $(\mathrm{SMN})$, and from 0.45 to $0.80( \pm 0.05)$ for the most peralkaline series (EBU). The effect of both oxygen fugacity conditions and alkali content on the Fe oxidation state can be clearly seen in Figure 5 for the three glass compositions. There is an evident net increase of the 
$\mathrm{Fe}^{3+} /\left(\mathrm{Fe}^{3+}+\mathrm{Fe}^{2+}\right)$ ratio increasing the $(\mathrm{Na}+\mathrm{K}) / \mathrm{Al}$ value from $1.04(\mathrm{ND})$ to 1.31 (SMN). On the other hand there is no marked variation as the $(\mathrm{Na}+\mathrm{K}) / \mathrm{Al}$ ratio is further increased from 1.31 to 1.81 (EBU). Within experimental error, the Fe oxidation states of the SMN and EBU series are very similar (Figure 5), however the EBU glasses display a sharp increase of the fraction of trivalent iron (from 0.52 ro $0.69 \pm 0.05$ ) at $\mathrm{f}_{\mathrm{O}_{2}}$ values ranging between -13 and -12.4 . Moreover, the EBU series displays more tetrahedral $\mathrm{Fe}^{3+}$ than SMN as evidenced by the higher pre-edge peak intensity of the EBU samples (see Figure 3).

As a significant fraction of the trivalent iron is tetrahedrally coordinated in the studied glasses, in going from reducing to oxidising conditions there is an overall increase of the tetrahedrally coordinated (network forming) Fe, which leads to a slight increase of the overall glass polymerisation. The EBU series has the lowest NBO/T values (Table 1), because all trivalent Fe is tetrahedrally coordinated.

EXAFS data confirmed that trivalent $\mathrm{Fe}$ is tetrahedrally coordinated in the most peralkaline glasses. For the most oxidised sample (EBU3) the determined $\langle\mathrm{Fe}-\mathrm{O}\rangle$ distance $(=1.84 \pm 0.02 \AA)$ is compatible to that of tetrahedrally coordinated trivalent iron in rodolicoite (1.8255 ̊; Arnold 1986) or in tetra-ferriphlogopite (1.86 ̊, Giuli et al. 2001). Also the refined coordination number is consistent with tetrahedral coordination $(4 \pm 0.5)$.

\section{ACKNOWLEDGEMENTS}

We wish to thank the staff of beam-line ID-26 (ESRF, F) for assistance during the XAS experiments. This research was supported by MIUR funds (Futuro in Ricerca 2008) to G.G.

\section{REFERENCES}


Brown, G.E., Farges, F., and Calas, G. (1995) X-ray scattering and X-ray spectroscopy studies of silicate melts. In: Stebbins J.F., McMillan P.F., Dingwell D. Eds., Structure, dynamics and properties of silicate melts. vol 32, 317-410. Reviews in Mineralogy, Mineralogical Society of America, Washington, D.C.

Calas, G., and Petiau, J. (1983a) Coordination of iron in oxide glasses through highresolution K-edge spectra: information from the pre-edge. Solid State Communications, 48, 625-629.

Calas, G., and Petiau, J. (1983b) Structure of oxide glasses: Spectroscopic studies of local order and crystallochemistry. Geochemical implications. Bulletin de Mineralogies, 106, 3355.

Cukierman, M., and Uhlmann, D.R. (1974) Effects of iron oxidation state on viscosity, Lunar composition 15555. Journal of Geophysical Research, 79, 1594-1598

Di Cicco, A., Berrettoni, M., Stizza, S., Bonetti, E., and Cocco. G. (1994) Microstructural defects in nanocrystaline iron probed by X-ray Absorption Spectroscopy. Physics Review B, $50,17,12386-12397$.

Dingwell, D.B. (1991) Redox viscometry of some Fe-bearing silicate melts. American Mineralogist, 76, 1560-1562.

Dingwell, D.B., Hess, K.-U., and Valenti, P. (2008) Oxidation state dependence of viscosity in peralkaline lavas: Phonolite and Pantellerite. American Geophysical Union, Fall Meeting 2008, Abstract V23G-2211.

Duffy, J.A. (1992) A review of optical basicity and its applications to oxidic systems.

Geochimica et Cosmochimica Acta, 57, 3961-3970.

Duffy, J.A. (1996) Redox equilibria in glass. Journal of Non-Crystalline Solids, 196, 45 50. 
Farges, F. (2001). Crystal-chemistry of Fe in natural grandidierites: a XAFS spectroscopy study at the Fe K-edge. Physics and Chemistry of Minerals, 28, 619-629.

Farges, F., Guyot, F., Andrault, D., and Wang, Y. (1994) Local structure around Fe in $\mathrm{Mg}_{0.9} \mathrm{Fe}_{0.1} \mathrm{SiO}_{3}$ perovskite: an X-ray absorption spectroscopic study at the $\mathrm{Fe} \mathrm{K}$-edge. European Journal of Mineralogy, 6, 303-312.

Filipponi, A. and Di Cicco, A. (2000) GNXAS: a software package for advanced EXAFS multiple-scattering calculations and data-analysis. Task Quarterly, 4, 575-669.

Gauthier, C., Solé, V.A., Signorato, R., Goulon, J. and Moguiline, E. (1999) The ESRF beamline ID26: X-ray absorption on ultra dilute sample. Journal of Synchrotron Radiation, 6, 164-166.

Giuli, G., Paris, E., Wu, Z., Brigatti, M.F., Cibin, G., Mottana, A., and Marcelli, A. (2001) Experimental and theoretical XANES and EXAFS study of tetra-ferriphlogopite. European Journal of Mineralogy, 13, 1099-1108.

Giuli, G., Pratesi, G., Paris, E., and Cipriani, C. (2002) Fe local structure in tektites and impactites by EXAFS and high-resolution XANES spectroscopy. Geochimica et Cosmochimica Acta 66: 4347-4353.

Giuli, G., Paris, E., Pratesi, G., Koeberl, C., and Cipriani C. (2003) Iron oxidation state in the Fe-rich layer and silica matrix of Libyan Desert Glass: a high resolution XANES study. Meteoritics and Planetary Sciences, 38, 1181-1186.

Giuli, G., Eeckhout, S.G., Paris, E., Koeberl, C., and Pratesi, G. (2005) Iron oxidation state in impact glass from the $\mathrm{K} / \mathrm{T}$ boundary at Beloc, Haiti, by high-resolution XANES spectroscopy. Meteoritics and Planetary Sciences, 40, 1575-1580.

Giuli, G., Eeckhout, S. G., Koeberl, C., Pratesi, C., and Paris, E. (2008) Yellow impact glass from the K/T boundary at Beloc (Haiti): XANES determination of the Fe oxidation state and implications for formation conditions. Meteoritics and Planetary Sciences, 43, 981-986. 
Giuli, G., Paris, E., Hess, K.U., Dingwell, D.B., Cicconi, M.R., Eckhout, S.G., Fehr, K.T., and Valenti, P. (2011) XAS determination of the Fe local environment and oxidation state in phonolite glasses and implications for the viscosity of silicate melts. American Mineralogist, 96, 631-636.

Jackson, W.E., Mustre de Leon, J., Brown, G.E., Jr., Waychunas, G.A., Conradsen, S.D., and Combes, J.M. (1993) High temperature XAS study of $\mathrm{Fe}_{2} \mathrm{SiO} 4$ : Evidence for reduced coordination of ferrous iron in the liquid. Science, 262, 229-233

Jackson, W.E., Farges, F., Yeager, M., Mabrouk, P.A., Rossano, S., Waychunas, G.A., Solomon, E.I., and Brown, G.E. JR. (2005) Multi-spectroscopic study of Fe(II) in silicate glasses: Implications for the coordination environment of Fe(II) in silicate melts. Geochimica et Cosmochimica Acta, 69, 4315-4332

Hedin, L., and Lundquist, B.I. (1971) Explicit local exchange-correlation potentials. Journal of Physics C 4, 2064.

Iwamoto, N., Tsunawaki, Y., and Nakagawa, H. (1978) Investigation of Calcium-ironsilicate glasses by the Mössbauer method. Journal of Non-Crystalline Solids, 29, 347-356.

Keppler, H. (1992) Crystal Field spectra and geochemistry of transition metal ions in silicate melts and glasses. American Mineralogist, 77, 62-75.

Krause, M.O., and Oliver, J.H. (1979). Natural widths of atomic K and L levels, K alpha X-ray lines and several KLL auger lines. Journal of Physical and Chemical Reference Data, 8, 329-338.

Magnien, V., Neuville, D.R., Cormier, Mysen, B.O., Briois, V., Belin, S., Pinet, O., Richet, P. (2004) Kinetics of iron redox reactions in silicate melts: a preliminary XANES study. Chemical Geology, 213, 253-263.

Moretti, R., and Ottonello, G. (2003) Polymerization and disproportionation of iron and sulfur in silicate melts: insights from an optical basicity based approach. Journal of Non- 
Crystalline Solids, 323, 111-119.

Mysen, B.O. and Richet, P. (2005) Silicate glasses and melts. Elsevier, Amsterdam, $545 \mathrm{p}$.

Scaillet, B., and Mc Donald, R. (2006) Experimental and thermodynamic constrains on the sulphur yield of peralkaline and metaluminous silicic flood eruptions. Journal of Petrology, 47, 1413-1437.

Shannon, R.D., and Prewitt, C.T. (1970) Revised values of effective ionic radii. Acta Crystallographica, B25, 925-946.

Solé, A.V., Gauthier, C., Goulon, J., and Natali, F. (1999). Undulator QEXAFS at the ESRF beamline ID26. Journal of Synchrotron Radiation, 6, 174-175.

Spiering, B., Seifert, F. (1985) Iron in silicate glasses of granitic composition: a Mössbauer spectroscopic study. Contribution to Mineralogy and Petrology, 90, 63-73

Stahl, K., and Legres, J-P. (1990) On the crystal structure of staurolite. The X-ray crystal structure of staurolite from the Pirenees and Brittany. Acta Crystallographica, B 46, 292-301.

Wilke, M., Farges, F., Petit, P.E., Brown, G.E., and Martin, F. (2001). Oxidation state and coordination of Fe in minerals: an Fe K-XANES spectroscopic study. American Mineralogist, 86, 714-730.

Wilke, M., Partzsch, G.M., Bernhardt, R., Lattard, D. (2004). Determination of the iron oxidation state in basaltic glasses using XANES at the K-edge. Chemical Geology 213, 7187.

Wilke, M., Schmidt, C., Farges, F., Malavergne, V., Gautron, L., Simionovici, A., Hahn, M., and Petit, P.E. (2006) Structural environment of Fe in water-bearing silicate glass and melt evidence from X-ray absorption spectroscopy. Chemical Geology, 229, 144-161. 


\section{Figure Captions}

Fig.1:

(a,b,c) Experimental Fe K-edge XANES spectra of synthetic glasses under study. Spectra arranged from bottom to top in order of increasing oxygen fugacity. The spectra are normalised to unit intensity at the high energy side. Variations of the pre-edge peak (P) intensity and energy position are evident in passing from reducing to oxidising conditions. a) ND series; b) SMN series; c) EBU series.

Fig. 2:

Background subtracted pre-edge peaks of the studied glasses (empty circles) along with the pseudo-Voigt component used in the fitting procedures (dotted lines), and pseudo-Voigt sums (solid lines). Each pre-edge peak could be fitted with three components. All series have been plotted with the same vertical scale so as to enable direct comparison of the raw intensities. a) ND series; b) SMN series; c) EBU series.

Fig. 3:

Plot of the pre-edge peak integrated intensity vs. centroid energy position. Solid squares refer to the ND series, whereas red diamonds refer to the SMN series and blue circles refer to the EBU series. The small diamonds joined by the dotted lines represent mixing lines of pre-edge peaks calculated mixing between ${ }^{[5]} \mathrm{Fe}^{2+}$ with ${ }^{[4]} \mathrm{Fe}^{3+}$ and/or ${ }^{[5]} \mathrm{Fe}^{3+}$. It is evident the shift to higher energy and intensity of these samples with increasing peralkalinity.

Fig. 4: 
Effect of alkali and oxygen fugacity on the Fe oxidation state for the three series of glasses. It can be clearly seen that there is a net increase of the $\mathrm{Fe}^{3+} /\left(\mathrm{Fe}^{3+}+\mathrm{Fe}^{2+}\right)$ ratio increasing the $(\mathrm{Na}+\mathrm{K}) / \mathrm{Al}$ ratio from 1.04 to 1.31 . On the other hand there is no marked variation as the $(\mathrm{Na}+\mathrm{K}) / \mathrm{Al}$ ratio is further increased from 1.31 to 1.81 .

\section{Fig. 5}

Comparison between the experimental, theoretical and residual Fe K-edge EXAFS signals of the EBU3 silicate glass. The EXAFS signals, in the energy range $7164.0-7650.0 \mathrm{eV}$ are weighted by $\mathrm{K}^{0}$. Symbols as follows: circles, experimental; solid line, theoretical; dotted line, residual. (a) EXAFS signals (b) Fourier transforms. The disagreement index (Rfit) is 0.59E05 . 
Table 1. Weight \% oxide composition of the studied glasses (From Scaillet and Mc Donald 2006)

\begin{tabular}{|c|c|c|c|c|c|c|c|c|c|c|c|c|c|c|c|c|}
\hline Sample & $\mathrm{SiO}_{2}$ & $\mathrm{Al}_{2} \mathrm{O}_{3}$ & $\mathrm{FeO}^{\mathrm{a}}$ & $\mathrm{Fe}_{2} \mathrm{O}_{3}{ }^{\mathrm{a}}$ & $\mathrm{CaO}$ & $\mathrm{MgO}$ & $\mathrm{K}_{2} \mathrm{O}$ & $\mathrm{Na}_{2} \mathrm{O}$ & $\mathrm{Cl}$ & $\mathrm{F}$ & $\mathrm{S}$ & total & $\mathrm{NBO} / \mathrm{T}^{\mathrm{b}}$ & $\begin{array}{c}\left(\mathrm{Na}_{2} \mathrm{O}+\mathrm{K}_{2} \mathrm{O}\right) \\
/ \mathrm{Al}_{2} \mathrm{O}_{3}\end{array}$ & $\begin{array}{c}(\mathrm{Na}+\mathrm{K}) / \\
\mathrm{Al}\end{array}$ & $\mathrm{Fe}^{3+} / \mathrm{Fe}^{\mathrm{tot} \mathrm{c}}$ \\
\hline ND1 & 77.25 & 12.08 & 0.31 & 0.09 & 0.37 & 0.05 & 5.00 & 4.54 & 0.13 & 0.13 & 0.03 & 99.98 & 0.08 & 0.79 & 1.07 & 0.21 \\
\hline ND2 & 77.18 & 12.17 & 0.29 & 0.11 & 0.35 & 0.05 & 4.98 & 4.55 & 0.13 & 0.13 & 0.03 & 99.97 & 0.08 & 0.78 & 1.06 & 0.25 \\
\hline ND4 & 77.25 & 12.19 & 0.39 & 0.16 & 0.30 & 0.04 & 4.76 & 4.54 & 0.15 & 0.18 & 0.03 & 99.99 & 0.08 & 0.76 & 1.04 & 0.27 \\
\hline ND6 & 77.43 & 12.16 & 0.55 & 0.36 & 0.03 & 0.03 & 4.55 & 4.51 & 0.11 & 0.16 & 0.05 & 99.93 & 0.06 & 0.75 & 1.02 & 0.37 \\
\hline ND3 & 77.33 & 12.19 & 0.39 & 0.43 & 0.01 & 0.02 & 4.67 & 4.53 & 0.05 & 0.25 & 0.06 & 99.94 & 0.06 & 0.75 & 1.03 & 0.5 \\
\hline SMN1 & 75.60 & 10.67 & 1.03 & 1.20 & 0.06 & 0.02 & 4.45 & 5.71 & 0.26 & 1.07 & 0.02 & 102.20 & 0.14 & 0.95 & 1.33 & 0.51 \\
\hline SMN4 & 75.23 & 10.75 & 0.86 & 1.78 & 0.03 & 0.01 & 4.33 & 5.70 & 0.22 & 1.20 & 0.04 & 102.60 & 0.12 & 0.93 & 1.31 & 0.65 \\
\hline SMN5 & 75.43 & 10.53 & 1.01 & 1.84 & 0.03 & 0.02 & 4.20 & 5.67 & 0.21 & 1.09 & 0.05 & 102.75 & 0.09 & 0.94 & 1.32 & 0.62 \\
\hline SMN6 & 76.51 & 10.73 & 0.52 & 1.18 & 0.01 & 0.00 & 4.24 & 5.65 & 0.08 & 1.08 & 0.05 & 101.63 & 0.08 & 0.92 & 1.29 & 0.67 \\
\hline SMN3 & 76.53 & 10.86 & 0.39 & 1.23 & 0.00 & 0.01 & 4.16 & 5.67 & 0.15 & 0.89 & 0.06 & 101.43 & 0.07 & 0.91 & 1.27 & 0.74 \\
\hline EBU1 & 74.09 & 8.30 & 2.85 & 2.60 & 0.23 & 0.01 & 4.41 & 6.52 & 0.35 & 0.79 & 0.07 & 100.22 & 0.03 & 1.32 & 1.87 & 0.45 \\
\hline EBU2 & 73.37 & 8.38 & 2.75 & 2.94 & 0.28 & 0.01 & 4.41 & 6.54 & 0.36 & 0.96 & 0.09 & 100.09 & 0.02 & 1.31 & 1.85 & 0.49 \\
\hline EBU4 & 73.75 & 8.29 & 2.65 & 3.20 & 0.14 & 0.01 & 4.19 & 6.50 & 0.23 & 0.82 & 0.09 & 99.87 & 0.02 & 1.29 & 1.84 & 0.52 \\
\hline EBU5 & 75.37 & 8.45 & 1.45 & 3.59 & 0.05 & 0.02 & 4.03 & 6.47 & 0.16 & 0.70 & 0.05 & 100.34 & 0.01 & 1.24 & 1.78 & 0.69 \\
\hline EBU6 & 75.65 & 8.46 & 1.20 & 3.59 & 0.02 & 0.02 & 4.05 & 6.46 & 0.12 & 0.66 & 0.04 & 100.27 & 0.01 & 1.24 & 1.77 & 0.73 \\
\hline
\end{tabular}

${ }^{\mathrm{a}} \mathrm{FeO}$ and $\mathrm{Fe}_{2} \mathrm{O}_{3}$ have been recalculated from the original data taking into account XANES determined $\mathrm{Fe}^{3+} / \mathrm{Fe}^{\text {tot }}$ ratios.

${ }^{\mathrm{b}}$ Calculated assuming tetrahedral coordination for $\mathrm{Si}$ and $\mathrm{Al}$ and using XANES determined Fe oxidation states and

coordination numbers ( $\mathrm{Fe}^{3+}$ all tetrahedrally coordinated for the EBU series).

${ }^{c}$ Determined by XANES comparing pre-edge peak data with those of Fe model compounds. Estimated error is \pm 0.05 
Table 2. Pre-edge peak data of the Fe K-edge XANES spectra

\begin{tabular}{|c|c|c|c|}
\hline Sample name & $\begin{array}{c}\text { Centroid } \\
(\mathrm{eV})^{\mathrm{a}}\end{array}$ & $\begin{array}{l}\text { Integrated } \\
\text { intensity }^{b}\end{array}$ & $\begin{array}{l}\text { Fit agreement } \\
\text { index }(\%)\end{array}$ \\
\hline \multicolumn{4}{|l|}{$\begin{array}{c}\text { Model } \\
\text { compounds }\end{array}$} \\
\hline Siderite & 7112.80 & 0.054 & 99.84 \\
\hline Kirschsteinite & 7113.00 & 0.062 & 99.83 \\
\hline Grandidierite & 7113.00 & 0.101 & 99.32 \\
\hline Staurolite & 7113.00 & 0.218 & 99.88 \\
\hline Fe-Akermanite & 7112.90 & 0.283 & 99.84 \\
\hline Andradite & 7114.40 & 0.107 & 99.93 \\
\hline Aegirine & 7114.51 & 0.103 & 99.97 \\
\hline Yoderite & 7114.30 & 0.169 & 99.91 \\
\hline $\begin{array}{l}\text { Tetra- } \\
\text { ferriphlogopite }\end{array}$ & 7114.53 & 0.401 & 99.97 \\
\hline \multicolumn{4}{|l|}{ Rhyolite glasses } \\
\hline ND1 & 7113.46 & 0.135 & 99.92 \\
\hline ND2 & 7113.57 & 0.152 & 99.97 \\
\hline ND4 & 7113.60 & 0.150 & 99.97 \\
\hline ND5 & 7113.65 & 0.150 & 99.98 \\
\hline ND6 & 7113.71 & 0.152 & 99.94 \\
\hline ND3 & 7113.89 & 0.145 & 99.93 \\
\hline SMN1 & 7113.92 & 0.168 & 99.97 \\
\hline SMN2 & 7113.97 & 0.186 & 99.97 \\
\hline SMN4 & 7114.06 & 0.210 & 99.96 \\
\hline SMN5 & 7114.05 & 0.179 & 99.99 \\
\hline SMN6 & 7114.18 & 0.193 & 99.99 \\
\hline SMN3 & 7114.14 & 0.205 & 99.97 \\
\hline EBU1 & 7113.94 & 0.194 & 99.90 \\
\hline EBU2 & 7114.00 & 0.198 & 99.90 \\
\hline EBU4 & 7114.08 & 0.235 & 99.88 \\
\hline EBU5 & 7114.12 & 0.287 & 99.94 \\
\hline EBU6 & 7114.26 & 0.283 & 99.98 \\
\hline EBU3 & 7114.28 & 0.297 & 99.97 \\
\hline
\end{tabular}


Table 3: Essential parameters of the EXAFS fit.

\begin{tabular}{|l|l|}
\hline$\langle\mathrm{Fe}-\mathrm{O}\rangle(\AA)$ & $1.84(0.02)$ \\
\hline$\sigma^{2}\left(\AA^{2}\right)$ & 0.0026 \\
\hline $\mathrm{N}$ & $4.0(0.5)$ \\
\hline$\langle\mathrm{Fe}-\mathrm{Si}\rangle(\AA)$ & 3.40 \\
\hline$\sigma^{2}\left(\AA^{2}\right)$ & 0.018 \\
\hline$\langle\mathrm{Fe}-\mathrm{Na}\rangle(\AA)$ & 4.77 \\
\hline$\sigma^{2}\left(\AA^{2}\right)$ & 0.019 \\
\hline $\mathrm{E}_{0} \operatorname{ref}(\mathrm{eV})^{*}$ & 7123.20 \\
\hline $\mathrm{E}_{0} \exp (\mathrm{eV})^{*}$ & 7120.41 \\
\hline $\mathrm{R}$ fit & $0.59 \mathrm{E}-05$ \\
\hline $\mathrm{S}_{0}{ }^{2}$ & 0.83 \\
\hline
\end{tabular}

$* \mathrm{E}_{0}$ exp: experimental edge energy;

$* \mathrm{E}_{0}$ ref: refined parameter for edge energy 